\title{
Ventajas nutritivas y terapéuticas del agua de mar en el Ecuador durante pandemia
}

\section{Nutritional and therapeutic benefits of seawater in Ecuador during a pandemic}

DOI: $10.46932 / \mathrm{sfjdv2n4-079}$

Received in: March 1st, 2021

Accepted in: May 30th, 2021

\author{
Hipatia Susana Campos Naula \\ BSD Berlin- IT Systenelektronikerin \\ Institución actual: Esencia Marina
}

Domicilio completo: 3.5Km entre Panamericana Sur y Camino Real Tisaleo, Santa Lucía - El Porvenir,

Tisaleo 180604 - Ambato- Provincia de Tungurahua.

Correo electrónico: hipatia.campos@gmail.com

\section{Ricardo Marcel Kluth Campos}

estudiante del sexto semestre de Bioquímica y Farmacia.

Institución actual: Escuela Superior Politécnica de Chimborazo

Domicilio completo: 3.5Km entre Panamericana Sur y Camino Real Tisaleo, Santa Lucía - El Porvenir,

Tisaleo 180604 - Ambato- Provincia de Tungurahua.

Correo electrónico: rikardo.kluth@ hotmail.com

\section{Damián Enrique Dattus Torres}

Doctor en ciencias de la Educación- Auxiliar en Farmacia

Institución actual: Servialfaro S. A. ( gerente)

Domicilio completo: calle 51 y av. Quito ( Salinas- Ecuador)

Correo electrónico: dandattor@gmx.es

\section{RESUMEN}

Las poblaciones ante la virulencia del COVID19 mostraron la pérdida de su bienestar y las opciones alimentarse adecuadamente para resistir al confinamiento, o para salvar vida pusieron en ejercicio a los conocimientos científicos de varios grupos de profesionales, que se encontraron ante un virus poco estudiado con una gran letalidad. Para ello se realizó una investigación analítica eligiendo la literatura científica de aplicación del francés Quinton, quien había descubierto las propiedades del agua de mar, y de algunas plantas medicinales. Se realiza una investigación de campo, orientada a establecer los beneficios anticoagulantes del agua de mar en un consumo adecuado de $30 \mathrm{ml}$ en las personas que alejadas de los fármacos acudieron a la misma como un recurso que mineralizó el cuerpo y sin saberlo al inició de la investigación evitó la coagulación de la sangre en personas que venían bebiendo agua de mar debidamente tratada. De esa manera, en forma inconsciente con los minerales que tenían en su cuerpo por la ingesta de agua de mar procesada, permitió que anticoagulantes naturales como el magnesio actuara como una barrera dentro de la cascada de coagulación, evitando que colapsen los pulmones por los componentes de la misma. La investigación tiene como objetivo establecer el aporte científico del conocimiento de la dosificación del agua de mar en el mejoramiento el bienestar y desarrollo de nuestros pueblos entrevistando a aquellos que la utilizaron para recoger información directa sobre sus beneficios orgánicos según su aplicación. Es un estudio cuantitativo y comparativo de las recomendaciones de la OMS se establecen las pautas mediante el proceso del método científico de observación, análisis, hipótesis y conclusiones. El análisis elige como tamaño de la muestra a 100 personas que se recuperaron luego de la administración del mar respaldado por un análisis de las historias clínicas y estudios de laboratorio 
luego de su aplicación. Entre los resultados está que el agua de mar ozonificada, en el 90\% de la población que mostró ahogamiento a partir de la segunda semana de virulencia al administrarse agua de mar, mostró recuperación a las 72 horas y un restablecimiento progresivo. En el estudio físico de la sangre durante y después de la administración del agua de mar, se observaron cambios en la coloración de la sangre y en la capacidad coaguladora.

Palabras claves: utilitarismo- agua de mar- anticoagulantes- plaquetas- heparina

\begin{abstract}
Populations in the face of the virulence of COVID19 showed the loss of their well-being and the options to eat properly to resist confinement, or to save life, put into practice the scientific knowledge of several groups of professionals, who were faced with a little-studied virus with a great lethality. For this, an analytical investigation was carried out choosing the scientific literature of the French Quinton, who had discovered the properties of seawater, and of some medicinal plants. A field investigation is carried out, aimed at establishing the anticoagulant benefits of seawater in an adequate consumption of $30 \mathrm{ml}$ in people who, away from drugs, resorted to it as a resource that mineralized the body and without knowing it at the beginning of the research prevented blood clotting in people who had been drinking properly treated seawater. In this way, unconsciously with the minerals that they had in their body from the intake of processed seawater, it allowed natural anticoagulants such as magnesium to act as a barrier within the coagulation cascade, preventing the lungs from collapsing due to the components Of the same. The objective of the research is to establish the scientific contribution of the knowledge of seawater dosage in improving the well-being and development of our peoples by interviewing those who used it to collect direct information on its organic benefits according to its application. It is a quantitative and comparative study of the WHO recommendations, the guidelines are established through the process of the scientific method of observation, analysis, hypotheses and conclusions. The analysis chooses as the sample size 100 people who recovered after the administration of the sea supported by an analysis of medical records and laboratory studies after its application. Among the results is that ozonated seawater, in $90 \%$ of the population that showed drowning from the second week of virulence when seawater was administered, showed recovery at 72 hours and a progressive recovery. In the physical study of the blood during and after the administration of seawater, changes in the color of the blood and in the coagulant capacity were observed.
\end{abstract}

Keywords: utilitarianism- seawater- anticoagulants- platelets- heparin

\title{
1 INTRODUCCIÓN
}

El cloro y el sodio, son solo una parte del agua de mar. Por lo tanto químicamente la sal al tener cloro y sodio representa la siguiente proporción: un litro de agua de mar de Esencia Marina ya tratada, contiene de la composición química de la sal( Cloruro de Sodio) De cloruros en agua=14791,00 mg en un litro; y de sodio contiene $1475 \mathrm{mg} /$ litro; en la suma da un valor de $(14791,00 \mathrm{mg}+1475 \mathrm{mg}=16.166$ $\mathrm{mg} /$ por litro)=1,6gr/ litro. Por lo tanto en $100 \mathrm{ml}$; hay $1,6 \mathrm{gr}$. ; y en $10 \mathrm{ml}=0,16$ gr. de Cloruros de agua con sodio. Esa es la barrera cultural del uso del agua de mar; porque ambas proposiciones: El agua de mar no es beneficiosa para el consumo humano, como la proposición El agua de mar es beneficiosa para el 
consumo humano, científicamente ambas proposiciones son falsas, si es que la proporción que se utiliza es o no es la conveniente, es decir tanto los excesos como la carencia deben esatr medidas objetivamente en mililitros y en gramos.

\section{ANTECEDENTES}

El año 2014 Denise Antionella Flórez y Bernabé Calle Blanca Valero, eran estudiantes de Ciencia y Tecnología de los Alimentos de la Facultad de Veterinaria de la Universidad Complutense de Madrid, y escribieron un artículo “El agua de mar en la alimentación y en la terapéutica” en el que entre los principales referencias y hallazgos están: El cloruro y el sodio son los elementos constituyentes fundamentales del agua de mar. (Flórez y Bernabé Calle 2015 ); y hacen una referencia a la historia de René Quinton y su uso.

La FAO como agencia de las Naciones Unidas publica en su página web citada en esta bibliografía, en su capítulo 10 el tema de los minerales. Haciendo un análisis del agua de mar que distribuye Esencia Marina en la Provincia de Tungurahua, se hace una analogía entre este artículo de las Naciones Unidas y el consumo alimenticio del agua de mar en el Ecuador. Lo que se descubre en el uso se dan barreras culturales, porque se cree que el agua de mar es bebible directamente del mar y no es así. Si bien muchos han sobrevivido es posible que al estar en alta mar, el agua de mar tenga menos impurezas.

Según la Organización de las Naciones Unidas para la alimentación, a través de la (FAO , 2018 ) «Los principales minerales del cuerpo humano son: calcio, fósforo, potasio, sodio, cloro, azufre, magnesio, manganeso, hierro, flúor, zinc, cobalto, y selenio.»( párr.3) De los cuales en un litro de agua de mar hipertónica tratada, el calcio está en 2000mg/ L, el fósforo en 0,12 mg/ en 100 g, el potasio, en 380 $\mathrm{mg} / \mathrm{L}$. Lo importante es conocer los elementos que contienenen los elementos para gestionar su alimentación.

\section{FUNDAMENTACIÓN TEÓRICA}

El cuerpo de un adulto medio contiene alrededor de $1250 \mathrm{~g}$ de calcio. Más de $99 \%$ del calcio se encuentra en los huesos y en los dientes, donde se combina con fósforo como fosfato de calcio. ( La cantidad de fósforo del agua de mar en un litro es de $0,12 \mathrm{mg} / 100 \mathrm{~g}$; y la de calcio es de $2000 \mathrm{mg} / \mathrm{litro}$ ) La suma de fósforo y calcio es 2,120 mg en un litro al combinarse forman ambos elementos; pero como no es en una combinación de laboratorio o en un tubo de ensayo, sino en forma libre y natural hay que considerar que el cloruro de agua y otros elementos de acuerdo a su valencia se están formando. (FAO , 2018 )

«Más del 99 por ciento del calcio se encuentra en los huesos y en los dientes, donde se combina con fósforo como fosfato de calcio, sustancia dura que le brinda rigidez al cuerpo. Sin embargo, 
aunque duro y rígido, el esqueleto no es la estructura sin cambios que parece ser. En realidad, los huesos son una matriz celular; el calcio se absorbe continuamente por los huesos y es devuelto al organismo. Los huesos, por lo tanto, sirven como reserva para suministrar este mineral.»( parr. 3)

Existen algunas restricciones para el uso deliberado del agua de mar sin un tratamiento adecuado, eso lo confirma un estudio realizado por (Jades Piedra, Jaden Piedra, Flores Mendieta , \& Vera Alava, 2018 ) sobre la Caracterización microbiológica de agua marina en zonas costeras de Manabí. En esta publicación, los autores detallan:

\begin{abstract}
Se han utilizado dos métodos de ensayo: Filtración por membrana y siembra de placa. Se han analizado los siguientes microorganismos aerobios mesófilos totales y enterobacterias, por la técnica de la siembra en placa; pseudomona aeruginosa, coliformes totales, mohos y levaduras por el método de flitración por membrana. Una carga microbiológica elevada en especial de coliformes totales es considerada como un factor de riesgo para los bañistas, en especial para la población susceptible a contraer enfermedades como mujeres embarazadas, niños y adultos mayores. (Jades Piedra, \& otros 2018 )
\end{abstract}

También, para la demostración de las dificultades del uso directo del agua de mar de las costas, y no tratadas, el SGI Alza como empresa calificadora de análisis, emite un informe del agua de mar el año 2020 en el que reconoce la presencia de heces fecales en el agua de mar no tratada, y recomienda un tratamiento que Esencia Marina cumple y que hizo favorable su uso.

Los resultados obtenidos, aunque son puntuales, reflejan la necesidad de implementar estrategias para la vigilancia, el seguimiento y control de este tipo de contaminantes de ocurrencia natural los cuales tienen implicaciones directas sobre la salud humana. Lo expresan autores como (Reyes Pérez, Quezada Viay , \& Moreno Lara , 2021) en la revista South Florida Journal of Development haciendo un análisis de la importancia de lo que se ingiere.

Detalla el informe de SGI Alza que «el agua de mar o agua salada es una disolución hecha o basada en agua que compone los océanos y mares de la Tierra. Es salada por la concentración de sales minerales disueltas que contiene, un 3,5\% es decir en cada litro de agua (1000 gramos) hay 35 gramos de sales disueltas, como media.»; pero en la cultura y comunidad científica hay una concepción 100\% errónea del agua de mar, tanto entre médicos, nutricionistas y autoridades de salud, con estudios no competentes, que creen que la ingesta de agua de mar implica un consumo de sodio de un 50\% y esa es una concepción y una proposición acientífica y empírica pura sin un racionalismo científico no neo positivista que revela que el agua de mar, según los informes de laboratorio revela que solo el 1,5\% es sodio, y el 14,791\% son cloruros agua,eso significa que el $\mathrm{Cl} \mathrm{Na}$ está con el hidrógeno y el oxígeno; lo que representa solamente una presencia del 15,03\% que representa la combinación cristalina del Cl Na en agua; aproximadamente, el resto son otro tipo de elementos. 
El sabor de la sal es uno de los más manifiestos pero no es por el sodio, sino por la combinación entre $\mathrm{Cl}$ y $\mathrm{Na}$. ; porque el sodio solo no tiene esa propiedad, sería algo así como la unión entre un hombre y una mujer para formar el cigoto, solos no se forma cigoto, igual ese sabor de $\mathrm{Cl}$ y $\mathrm{Na}$, da el sabor a sal; pero hay más elementos, por eso el sabor de agua de mar se puede decir que es salado, y el sufijo -ado en este caso no significa sal, sino «que ha recibido la acción de la sal »es decir salado significa químicamente, que ha recibido la acción de la sal, no que es sal, son químicamente diferentes.

Haciendo una analogía entre un hijo y un padre, pero el hijo ónticamente no es el padre, como el agua salada no es la sal; por eso, por los criterios errados que han acompañado a la humanidad por siglos, se hace necesario que quien maneje el consumo de agua de mar, se lo haga desde la Educación para la Salud, y domine muy bien al menos la química inorgánica para que razonando el poder de las valencias de los elementos determine mentalmente cómo los elementos como: K, Fe, I, Ca, Mg, Mn, Z, Ag, Na, $\mathrm{P}, \mathrm{S}, \mathrm{Se}, \mathrm{Co}, \mathrm{Cu}, \mathrm{Li}, \mathrm{B}, \mathrm{Si}$,cloruros de agua y floruros se unen en una sola solución que es el agua de mar. De estos elementos se va a establecer los criterios científicos de cada elemento: sus ventajas y las desventajas de su uso mayor a una cucharada sopera que corresponde a $15 \mathrm{ml}$. Por ejemplo: 1 litro de agua de mar contiene $380 \mathrm{mg} / \mathrm{l}$ de potasio( $\mathrm{K}$ ) entonces se convierte en una regla de tres:

Si en $1000 \mathrm{ml}$ de agua de mar hay $380 \mathrm{mg}$ de potasio

En $15 \mathrm{ml}$ de agua de mar $\mathrm{X}$

$=5700 \mathrm{ml} / \mathrm{mg} \div 1000 \mathrm{ml}=5,7 \mathrm{mg} ;$ que corresponden al valor de potasio que hay en una cucharada sopera. Eso demuestra que más que prohibir el uso de agua de mar procesada, se debe prohibir es el uso de agua de mar no tratada, además de que las universidades deben abrir las puertas para que las investigaciones aumenten a más hacia encontrar más de lo que la presente investigación aporta a la química moderna. Si un paciente no puede recibir más de $5,7 \mathrm{mg}$ de potasio en 24 horas, entonces el 5 límite mayor debe es de 1 cucharada de agua de tratada máxima en 24 horas.

En relacián al boro, actúa siempre con valencia . Su estado de oxidación es + 3. En el análisis del boro a nivel de célula vegetal, el boro desempeña un papel esencial en el transporte de azúcares, en la síntesis de sacarosa, en el metabolismo de ácidos nucleicos, en la biosíntesis de carbohidratos, en la fotosíntesis, en el metabolismo proteico, en la síntesis y estabilidad de las paredes y membranas celulares, etc. En los vegetales, un efecto de la deficiencia de boro es la inhibición de la síntesis de ARN y ADN. La alteración es la síntesis de ARN puede deberse a la esencialidad del boro en la síntesis de bases nitrogenadas como el uracilo. De esta forma, los ribosomas no se pueden formar, y, en consecuencia, la síntesis de proteínas es afectada adversamente.

En los Archivos Latinoamericanos de Nutrición (García Casal, y otros, 2013) escribieron el tema: «Valores de referencia de hierro, yodo, selenio, cobre, molibdeno, vitamina C, vitamina $\mathrm{E}$, vitamina $\mathrm{K}$, 
carotenoides y polifenoles para la población venezolana »; en el que se estudia el yodo, selenio y cobre que son tres elementos químicos en forma de minerales, que forman parte del agua de mar. Cristalográficamente, el cromo tiene 0,289 nanómetros, el hierro 0,287 nanómetros en su constante de red. El potasio es uno de los que más alta tiene su constante de red que medida en nanómetros es de 0,533, el sodio es de 0,429 y ha sido una de las causas para que en caso del daño renal, no ha podido filtrar fácilmente. Siendo a su vez la preocupación médica para la ingesta del agua de mar. Si se consigue un análisis de los alimentos que la persona está consumiendo durante el tratamiento de agua de mar, se evitará el uso indiscriminado del agua de mar en forma acientífica. No es que el agua de mar ingerida dosificadamente haga daño, no, eso es una falacia; pero también es una falacia, dejar su ingesta sin una recomendación del nutricionista, del pediatra, del nefrólogo en forma científica.

En $100 \mathrm{~g}$. de sal de mesa hay 38,758mg de sodio que equivale a 38, 7 gramos de sodio. Por lo que en 10 gramos de sal de mesa hay $3,87 \mathrm{mg}$ de sodio que corresponde a una cuchara rasa. Por eso hay que considerar la cultura alimenticia para determinar el consumo de agua de mar en relación a la sal de mesa para el manejo correcto del sodio y de otros elementos, con una diferenciación entre sierra y costa, además de si es de lunes a viernes o es fin de semana, por situaciones culturales; por ejemplo en España el fin de semana la mayoría de las personas descansan del trabajo, otras salen a las terrazas. En la costa ecuatoriana, en el estudio del comportamiento social de la Provincias de Santa Elena y Guayas, las familias celebran el San Viernes o las fiestas donde se consume más cantidad de sodio y grasas. Igual sucede en provincias como Tungurahua, lugar donde se ha realizado el análisis del consumo de agua de mar durante y después del uso de la vacunación masiva que comenzó en forma más efectiva a partir de julio de 2021.

En 1.992, bajo el auspicio de la OMS (Organización Mundial de la Salud), el Comité Internacional para el Control de los Trastornos por Déficit de Yodo, la Asociación Europea de Tiroides, la Comisión de la Comunidad Europea y UNICEF fijaron las siguientes recomendaciones:Niños prematuros 90 Ug/día-Niños hasta 6 años 90 Ug/día-Niños de 7 a 10 años 120 Ug/día- Adultos 150 Ug/día- Embarazadas y período de lactancia 200 Ug/día (Sánchez Quezada, 2018)

Dentro de la Educación para la salud, luego del mito y las muchas falacias que se han dicho al respecto, vale la pena que el factor de la comunicación científica se imponga, tal como se lo hace con una ampicilina, una neurobion. La sociedad moderna al tener a la mano alimentos a los que en siglos anteriores les era muy difícil obtenerlos, actúa desenfrenadamente en su uso, pero no es problema del agua de mar, sino de aquellos que sin conocer las bondades, sataniza su uso. Es como si se quisiera prohibir el uso de la calidad del aire, solo porque el aire es de tipo natural y no es tan comercializable. Sin embargo el agua de mar, la de la orilla, no es recomendable. En el Ecuador, los puertos petroleros, hacen que el agua de mar, se convierta en no bebible. 
Las empresas que las comercializan como Esencia Marina, se abastece de agua de mar mínimo a $10 \mathrm{~km}$ de la orilla, para luego ser procesada. Algunos insinúan que el agua de mar pierde las propiedades naturales al ser tratada, pero los informes científicos, químicos y físico químicos obligan a su tratamiento por las impurezas que puede tener. En países donde el agua de mar es cuidada con mayor ahínco igual debe ser procesada por la presencia continua de impurezas como consecuencia del acceso de humanos y animales a sus costas o fuera de ellas.

Las principales hormonas tiroideas secretadas por la tiroides son la tiroxina y la triyodotironina, son aminoácidos yodados sintetizados en el coloide por yodación y condensación de moléculas de tirosina que están unidas por enlace peptídico a la tiroglobulina. Esta es la proteína específica de la tiroides, componente principal del coloide, que constituye el $75 \%$ de las proteínas. (Esteva , 2017)

Como el organismo tiene una cantidad total de 3000 - $4000 \mathrm{mmol}$ de potasio y la mayor parte de mismo es intracelular; el potasio que aporta el agua de mar con $380 \mathrm{mg} / 1$ al consumir $10 \mathrm{ml}$ de agua de mar en una cuchara, actúa como un complemento alimenticio en esa cantidad; pero en otros casos como por ejemplo al ser ingerida durante la pandemia, el agua de mar, no actuó como un complemento alimenticio, del que depende también la actividad económica a la que se dedique la persona; por lo tanto en la ingesta de agua de mar, no es la misma cantidad a ingerir para todos.

El sodio, el potasio y el cloro están presentes como sales en los líquidos corporales, donde tienen la función fisiológica de mantener la presión osmótica. (FAO, 2018 ) El calcio y el fósforo en los huesos se combinan para dar soporte firme a la totalidad del cuerpo. Los minerales se encuentran en los ácidos corporales; por ejemplo, el cloro está en el ácido clorhídrico del estómago. Son también constituyentes esenciales de ciertas hormonas, por ejemplo el yodo,

En forma de cloruro de sodio que se conoce como la sal común, representa el $80 \%$ de la solución. Esas cantidades y la composición de cloruro y sodio en el agua de mar es muy semejante a la de los líquidos orgánicos como la sangre, los líquidos viscerales que forman el medio interno de los animales y que juegan un papel decisivo en la fisiología. (Flórez y Bernabé Calle 2015 )( p.30)

La presencia de silicio en el agua de mar es de 125mg/ 1; y entre los pacientes refieren aumento de vitalidad ante el consumo de agua de mar. Para (Aguirre, Chávez, García , \& Raya , 2007 )

En ausencia de Silicio las plantas vasculares son más vulnerables a patógenos, insectos fitófagos y hervíboros. El Si les confiere resistencia al estrés biótico y abiótico(...) También, en animales se han reconocido las funciones del Silicio, principalmente en la formación de huesos y respuesta inmune. ( p.1)

Las tasas de absorción de silicio varían según el estado del ciclo celular, además, las células pueden absorber mayor cantidad de sílice del que necesitan acumulándolo en su interior. (Aguirre , Chávez , 
García , \& Raya , 2007 ) Esa es la forma como el agua de mar actúa a nivel de células malignas, que absorben la sílice, y el nitrógeno a menor velocidad provocando su efecto terapéutico. «La asimilación de $\mathrm{Si}$ por seres vivos ocurre en una amplia variedad de organismos, incluyendo diatomeas, esponjas, moluscos y plantas superiores» (Lowenstam, 1981; Simpson y Volcani, 1981). (Aguirre , Chávez, García , \& Raya , 2007 ); situación que también hay que considerar en la ingesta de agua de mar y en las administraciones no tradicionales. Recordar que el silicio en un recipiente de un litro de agua de mar, su valor es de ser de $125 \mathrm{mg}$.

Para (Ramírez, y otros, 2009 )

El silicio es el segundo componente más importante de la corteza terrestre después del oxígeno. (...) El silicio diseuelto en el agua $\mathrm{Si}(\mathrm{Oh})_{4}$ ( ácido ortosilícico) tiene una concetración variable que es mayor en aguas continentales y por lo general se haya en exceso con respecto al nitrógeno y al fósforo, salvo en lugares de vertederos de basura. (...) Existen diferencias entre la absorción de la sílice con respecto a la del $\mathrm{P}$ o $\mathrm{N}$.

\section{Hipótesis:}

Existe una ventaja nutritiva y terapéutica en el consumo de agua de mar

Tabla 1 Variables de la Investigación

\begin{tabular}{|c|c|c|c|}
\hline $\begin{array}{l}\text { Variables } \\
\text { Variable } \\
\text { dependiente: } \\
\text { Ventajas nutrutivas } \\
\text { y terapéutica }\end{array}$ & Dimensiones & Indicadores & Indices \\
\hline \multirow[t]{3}{*}{$\begin{array}{l}\text { Variable } \\
\text { dependiente: } \\
\text { Ventajas nutrutivas } \\
\text { y terapéutica }\end{array}$} & \multirow{3}{*}{$\begin{array}{l}\text { Biológica } \\
\text { Química } \\
\text { Farmacológica }\end{array}$} & \multirow{2}{*}{$\begin{array}{l}\text { Vitalidad } \\
\text { Poder de sus } \\
\text { elementos }\end{array}$} & \multirow{3}{*}{$\begin{array}{l}\text { Personas de todas las edades con } \\
\text { vitalidad } \\
\text { Síntomas parecidos en muestras } \\
\text { desconocidas }\end{array}$} \\
\hline & & & \\
\hline & & $\begin{array}{l}\text { Efecto } \\
\text { farmacocinético y } \\
\text { farmacodinámico }\end{array}$ & \\
\hline $\begin{array}{l}\text { Variable } \\
\text { dependiente: } \\
\text { Consumo de agua } \\
\text { de mar hipertónica } \\
\text { procesada }\end{array}$ & Cultural & $\begin{array}{l}\text { Consumo } \\
\text { equivocado }\end{array}$ & $\begin{array}{l}\text { Cerca de } 200 \text { personas que veían como } \\
\text { un tabú mejoraron y testimonian } \\
\text { documentalmente con cédula de } \\
\text { identidad su mejoría cerca de } 200 \\
\text { personas. } \\
\text { La consumieron cerca de } 40 \text { mil } \\
\text { personas en plena pandemia desde el } \\
2019 \text { al } 2020 \text { entre servidores públicos, } \\
\text { médicos, terapeutas, jueces, abogados, } \\
\text { docentes y se salvaron. }\end{array}$ \\
\hline
\end{tabular}




\begin{tabular}{|l|l|l|l|}
\hline Económico & $\begin{array}{l}\text { Desplaza } \\
\text { medicamentos } \\
\text { tradicionales }\end{array}$ & $\begin{array}{l}\text { Se pudo consumir junto con unos } \\
\text { alimentos en su mayoría y otros no. }\end{array}$ \\
\hline
\end{tabular}

Elaborado por: Hipatia Campos

\section{METODOLOGÍA}

\subsection{POBLACIÓN Y MUESTRA}

Para demostrar el papel decisivo en la fisiología, se escogieron de una población infinita de enfermos de Covid 19 al azar 100 muestras distribuidas geográficamente en algunas de las provincias del Ecuador, que habían consumido agua de mar antes de la pandemia, y durante la pandemia; y otras que la utilizan en la preparación de alimentos. Es una investigación cuantitativa, de campo y bibliográfica, porque selecciona los procesos demostrativos comparando resultados desde la vertiente de la manipulación de la muestra. Entre las técnicas están las del interrogatorio a la población de personas que han experimentado el agua de mar como medida nutritiva y terapéutica.

La población está conformada por personas que consumen agua de mar, a sobrevivientes del Covid 19 de las provincias de Chimborazo, de Imbabura, Pichincha, Tungurahua y Cotopaxi.

Para la validación del efecto del agua de mar, se entrevistaron a 100 personas, que consumen periódicamente el agua de mar desde 2018, aquellos cuyos ascendientes tienen o tuvieron cáncer de tiroides, aquellos que padecieron y sobrevivieron al COVID 19, superaron el Covid 19, SarsCov2 con la administración de $60 \mathrm{ml}$ diarios de agua de mar, por seis días consecutivos. En la dosis de $60 \mathrm{ml} / 1000=$ 0,06 litros; y en los equivalentes de cada uno de los elementos que contiene 1 litro de agua de mar, se hace la siguiente conversión:

Tabla 2 Dosificación del agua de mar hipertónica de acuerdo a las necesidades metabólicas

\begin{tabular}{|l|l|l|l|l|l|}
\hline $\begin{array}{l}\text { Elemento del } \\
\text { agua de mar en } \\
\text { solución } \\
\text { hipertónica }\end{array}$ & $\begin{array}{l}\mathbf{1} \text { litro de agua } \\
\text { de mar } \\
\text { hipertónica } \\
\text { tratada }\end{array}$ & $\begin{array}{l}\mathbf{1 0 0} \text { ml de agua } \\
\text { de mar } \\
\text { hipertónica } \\
\text { tratada }\end{array}$ & $\mathbf{6 0 ~ m l}$ & $\mathbf{2 0 ~ m l ~}$ & (5 ml \\
\hline Potasio & $380,00 \mathrm{mg} / \mathrm{L}$ & $38,00 \mathrm{mg}$ & $22,889 \mathrm{mg}$ & $7,6 \mathrm{mg}$ & $5,7 \mathrm{mg}$ \\
\hline Hierro & $29,54 \mathrm{mg} / \mathrm{L}$ & $2,95 \mathrm{mg}$ & $1,77 \mathrm{mg}$ & $0,57 \mathrm{mg}$ & $0,44 \mathrm{mg}$ \\
\hline Yodo & $0,001 \mathrm{mg} / \mathrm{L}$ & $0,0001 \mathrm{mg}$ & $0,00006 \mathrm{mg}$ & $0,00002 \mathrm{mg}$ & $0,000015 \mathrm{mg}$ \\
\hline 2-Calcio & $2000 \mathrm{mg} / \mathrm{L}$ & $200,0 \mathrm{mg}$ & $120,00 \mathrm{mg}$ & $40,00 \mathrm{mg}$ & $30,00 \mathrm{mg}$ \\
\hline 5-Magnesio & $607,75 \mathrm{mg} / \mathrm{L}$ & $60,775 \mathrm{mg}$ & $36,465 \mathrm{mg}$ & $12,15 \mathrm{mg}$ & $36,465 \mathrm{mg}$ \\
\hline Manganeso & $<0,01 \mathrm{mg} / \mathrm{L}$ & $<0,001 \mathrm{mg} / \mathrm{L}$ & $<0,0006 \mathrm{mg}$ & $<0,0002 \mathrm{mg}$ & $<0,00015 \mathrm{mg}$ \\
\hline Zinc & $0,015 \mathrm{mg} / \mathrm{L}$ & $0,15 \mathrm{mg} / \mathrm{L}$ & 0,0009 & 0,0003 & 0,000225 \\
\hline Plata & $<0,01 \mathrm{mg} / \mathrm{L}$ & $<0,001 \mathrm{mg} / \mathrm{L}$ & $<0,0006$ & $<0,0002$ & $<0,00015$ \\
\hline 3- Sodio & $1475 \mathrm{mg} / \mathrm{L}$ & $147 \mathrm{mg} / \mathrm{L}$ & 88,5 & 29,5 & 22,12 \\
\hline Fósforo & $0,12 \mathrm{mg} / 100 \mathrm{~g}$ & $0,012 \mathrm{mg} / 100 \mathrm{~g}$ & 0,0072 & 0,0024 & 0,0018 \\
\hline 4-Azufre & $865.00 \mathrm{mg} / \mathrm{L}$ & $86,50 \mathrm{mg} / \mathrm{L}$ & 51,9 & 17,3 & 12,975 \\
\hline Selenio & $<0,010 \mathrm{mg} / \mathrm{L}$ & $<0,0010 \mathrm{mg} / \mathrm{L}$ & $<0,0006$ & $<0,0002$ & $<0,00015$ \\
\hline Cobalto & $<0,10 \mathrm{mg} / \mathrm{L}$ & $<0,010 \mathrm{mg} / \mathrm{L}$ & 0,006 & 0,002 & 0,0015 \\
\hline Cobre & $14,5 \mathrm{mg} / \mathrm{L}$ & $1,45 \mathrm{mg} / \mathrm{L}$ & 0,87 & 0,29 & 0,2175 \\
\hline Litio & $0,189 \mathrm{mg} / \mathrm{L}$ & $0,0189 \mathrm{mg} / \mathrm{L}$ & 0,01134 & 0,00378 & 0,002835 \\
\hline
\end{tabular}




\begin{tabular}{|l|l|l|l|l|l|}
\hline Boro & $2,50 \mathrm{mg} / \mathrm{L}$ & $0,250 \mathrm{mg} / \mathrm{L}$ & 0,15 & 0,05 & 0,0375 \\
\hline Silicio & $125 \mathrm{mg} / \mathrm{L}$ & $12,5 \mathrm{mg} / \mathrm{L}$ & 7,5 & 2,5 & 1,875 \\
\hline 1-Cloruros agua & $14791,00 \mathrm{mg} / \mathrm{L}$ & $\begin{array}{l}1.4791,00 \\
\mathrm{mg} / \mathrm{L}\end{array}$ & 887,46 & 295,82 & 221,86 \\
\hline Fluoruros & $3,15 \mathrm{mg} / \mathrm{L}$ & $0,315 \mathrm{mg} / \mathrm{L}$ & 0,189 & 0,063 & 0,04725 \\
\hline
\end{tabular}

Elaborada por: Hipatia Campos

Compuestos que se forman en el agua de mar:

1-CaCl2 (cloruro de calcio)

2- Cloruro de sodio

3- SCl2 (cloruro de azufre) formado por cloruros y sulfatos

4- $\mathrm{MgCl} 2$ (cloruro de magnesio)

El agua de mar de Esencia Marina, la empresa en la que se ha hecho la experimentación contiene seis metales alcalinos de la tabla periódica: Potasio ( K) con $380 \mathrm{mg} /$ litro en agua de mar, Na ( sodio) con $1475 \mathrm{mg}$ por litro que equivale a 1,475 gr. Contiene Litio con 0,189 mg / L; hasta el momento.

El yodo, que es esencial para la síntesis de la hormona tiroidea, entra en el organismo a través del agua y los alimentos( las necesidades diarias de yodo son de 100 a 200 microgramos al día) y un litro de agua de mar, proporcionan apenas $0,001 \mathrm{mg}$ por litro de yodo; que equivale a la centésima parte de lo que el organismo necesita, por eso se debe complementar con otras fuentes de yodo, sobre todo en la alimentación. $1 \mathrm{gr}=1000 \mathrm{mg}=1000000 \mathrm{ug}$. Por lo tanto en forma diaria, un litro de agua de mar en los alimentos es permitida. ¿ Pero cómo debe ser esa ingesta en casos de patologías preexistentes? En el desayuno, puede entrar en la preparación del huevo, como agua isotónica, ya que se ha preparado de la siguiente manera: $60 \%$ de agua potable ( $30 \mathrm{ml}$ ), 40\% de agua de mar en una sartén ( $20 \mathrm{ml})$. Con esa cantidad de líquido, el agua de mar isotónica permitió alcanzar un punto de sabor adecuado a alimentos como huevos, carne, pescado, con bajo contenido de sodio, y los valores de los minerales de:

Tabla 3 Distribución de minerales de agua de mar de Esencia Marina en $20 \mathrm{ml}$

\begin{tabular}{|l|l|l|l|}
\hline Potasio & $7,6 \mathrm{mg}$ & Azufre & $17,3 \mathrm{mg}$ \\
\hline Hierro & $0,57 \mathrm{mg}$ & Selenio & $<0,0002$ \\
\hline Yodo & $0,00002 \mathrm{mg}$ & Cobalto & $0,002 \mathrm{mg}$ \\
\hline Calcio & $40,00 \mathrm{mg}$ & Cobre & $0,29 \mathrm{mg}$ \\
\hline Magnesio & $12,15 \mathrm{mg}$ & Litio & $0,00378 \mathrm{mg}$ \\
\hline Manganeso & $<0,0002 \mathrm{mg}$ & Boro & $0,05 \mathrm{mg}$ \\
\hline Zinc & $0,0003 \mathrm{mg}$ & Silicio & $2,5 \mathrm{mg}$ \\
\hline Plata & $<0,0002 \mathrm{mg}$ & Cloruros agua & 295,82 \\
\hline Sodio & $29,5 \mathrm{mg}$ & Fluoruros & $0,063 \mathrm{mg}$ \\
\hline Fósforo & $0,0024 \mathrm{mg}$ & \multicolumn{3}{|l}{} \\
\cline { 1 - 3 }
\end{tabular}

Esa es la cantidad de minerales que corresponden aproximadamente a 2 cucharadas grandes de agua de mar para realizar la cocción en un sartén que no contiene el aceite tradicional. Se unieron dos 
densidades diferentes, para formar una sola película. Se hizo la experimentación con pescado bonito, corvina y carnes de res y borrego, con huevos de gallina.

\section{RESULTADOS}

\section{1¿Qué alimentos ha preparado con agua de mar?}

Tabla 4 Alimentos preparados con agua de mar

\begin{tabular}{|l|c|c|c|c|}
\hline Categorías & Frecuencia & $\begin{array}{l}\text { Frecuencia } \\
\text { acumulada }\end{array}$ & Porcentaje & $\begin{array}{c}\text { Porcentaje } \\
\text { acumulado }\end{array}$ \\
\hline Pollo en sartén & $\mathbf{1 2}$ & $\mathbf{1 2}$ & $\mathbf{1 2}$ & $\mathbf{1 2}$ \\
\hline Huevos en sartén & $\mathbf{1 2}$ & $\mathbf{2 4}$ & $\mathbf{1 2}$ & $\mathbf{2 4}$ \\
\hline Pescado en sartén & $\mathbf{1 1}$ & $\mathbf{3 5}$ & $\mathbf{1 1}$ & $\mathbf{3 5}$ \\
\hline Piña con agua de mar & $\mathbf{3}$ & $\mathbf{3 8}$ & $\mathbf{3}$ & $\mathbf{3 8}$ \\
\hline Mango con agua de mar & $\mathbf{2}$ & $\mathbf{4 0}$ & $\mathbf{2}$ & $\mathbf{4 0}$ \\
\hline Arroces & $\mathbf{2 1}$ & $\mathbf{6 1}$ & $\mathbf{2 1}$ & $\mathbf{6 1}$ \\
\hline Corvina con agua de mar & $\mathbf{1 2}$ & $\mathbf{7 3}$ & $\mathbf{1 2}$ & $\mathbf{7 3}$ \\
\hline Bonito con agua de mar & $\mathbf{4}$ & $\mathbf{7 7}$ & $\mathbf{4}$ & $\mathbf{7 7}$ \\
\hline Ensaladas & $\mathbf{2 3}$ & $\mathbf{2 3}$ & $\mathbf{2 3}$ & $\mathbf{2 3}$ \\
\hline Total & $\mathbf{1 0 0}$ & & $\mathbf{1 0 0}$ & \\
\hline & & & & \\
\hline
\end{tabular}

Son múltiples los alimentos preparados con el agua de mar, elaborados desde la cultura alimenticia, con esa visión culinaria, el instrumento del agua de mar, ha servido como un amortiguador del exceso de cloro y sodio que contiene la sal común para los hipertensos y los diabéticos. Así el tradicional pollo, los huevos, la piña o el mango han sido modificados en la forma de administrarse esa materia prima de la alimentación cambiándole el agua de mar como un nueva solución en vez del aceite o del agua potable. Así el 100\% de los platos que utilizan en la forma son de innovación en la administración de los alimentos.

2. ¿Qué bondades ha escuchado o leído en las que tiene efecto positivo el consumo adecuado de agua de mar debidamente tratada?

Tabla 5 Bondades del agua de mar

\begin{tabular}{|l|c|c|c|c|}
\hline Categorías & Frecuencia & $\begin{array}{l}\text { Frecuencia } \\
\text { acumulada }\end{array}$ & Porcentaje & $\begin{array}{l}\text { Porcentaje } \\
\text { acumulado }\end{array}$ \\
\hline Cansancio & 32 & 32 & 32 & 32 \\
\hline Anti coagulante pulmonar & 46 & 78 & 46 & 78 \\
\hline Cáncer de próstata & 3 & 81 & 3 & 81 \\
\hline Miomas & 5 & 86 & 5 & 86 \\
\hline Cálculos de vesícula biliar & 6 & 92 & 6 & 92 \\
\hline Cálculos renales & 8 & 100 & 8 & 100 \\
\hline Total & 100 & & 100 & \\
\hline
\end{tabular}

Los encuestados manifiestan la calidad de vida que tienen a partir del agua de mar comprada, dosificada. El efecto mineralizante de la misma actúa a nivel intracelular yendo a cumplir las propiedades 
que la caracterizan hacia el cálculo renal, el coágulo que formó las proteínas del virus covid 19 además de ir contra la malignidad de la célula maligna en cáncer cambiándole el ph de la zona afectada y muriendo la misma.

3.- ¿Qué órganos o partes del cuerpo fueron los más beneficiados después del consumo de agua de mar?

Tabla 6 Partes del cuerpo

\begin{tabular}{|l|l|l|l|l|}
\hline Categorías & Frecuencia & $\begin{array}{l}\text { Frecuencia } \\
\text { acumulada }\end{array}$ & Porcentaje & $\begin{array}{l}\text { Porcentaje } \\
\text { acumulado }\end{array}$ \\
\hline Riñones & 19 & 19 & 19 & 19 \\
\hline Cerebro & 37 & 56 & 37 & 56 \\
\hline Vesícula biliar & 14 & 70 & 14 & 70 \\
\hline Órgano reproductor & 12 & 82 & 12 & 82 \\
\hline Articulaciones & 18 & 100 & 18 & 100 \\
\hline Total & 100 & & 100 & \\
\hline
\end{tabular}

Los resultados demuestran que el cerebro se ha nutrido de los minerales que proporciona el agua de mar así como la vitalidad sexual en 12 personas se ha mantenido en forma satisfactoria, la vesícula biliar, y los riñones se han visto ayudados por el poder que tiene el magnesio como elemento importante en la calidad de estos órganos. El 19\% informa de su bienestar renal y el $18 \%$ bienestar a nivel de articulaciones.

\section{4.- ¿Cómo influenció el agua de mar ante la preparación de alimentos sólidos o líquidos?}

Tabla 7 Agua de mar con los alimentos

\begin{tabular}{|l|c|c|c|c|}
\hline Categoría & Frecuencia & $\begin{array}{l}\text { Frecuencia } \\
\text { acumulada }\end{array}$ & Porcentaje & $\begin{array}{l}\text { Porcentaje } \\
\text { acumulado }\end{array}$ \\
\hline $\begin{array}{l}\text { Buena calidad de la } \\
\text { presentación de los alimentos }\end{array}$ & 20 & 20 & 20 & 20 \\
\hline Disminuye lo soso del sabor & 5 & 25 & 5 & 25 \\
\hline $\begin{array}{l}\text { Luego de consumir los } \\
\text { alimentos con agua de mar } \\
\text { baja el insomnio }\end{array}$ & 20 & 45 & 20 & 45 \\
\hline Mejora del estado general & 11 & 56 & 11 & 75 \\
\hline $\begin{array}{l}\text { Sabor agradable de los } \\
\text { alimentos }\end{array}$ & 19 & 75 & 83 & \\
\hline $\begin{array}{l}\text { Luego de la ingesta de los } \\
\text { alimentos con agua de mar, se } \\
\text { regula la presión arterial }\end{array}$ & 8 & 83 & 70 \\
\hline $\begin{array}{l}\text { Los alimentos se preparan con } \\
\text { menos aceite }\end{array}$ & 7 & 90 & 7 & 100 \\
\hline $\begin{array}{l}\text { Vitalidad luego de ingerir los } \\
\text { alimentos con agua de mar }\end{array}$ & 10 & 100 & 100 & \\
\hline Total & 100 & & & \\
\hline
\end{tabular}


El bienestar que produce una alimentación de la preparación de los productos con agua de mar, es de un $73 \%$. Estos resultados se asocian a la calidad terapéutica que ha representado su uso para la alimentación. Incluso la vitalidad de la que se refiere en la pregunta anterior, continúa su confirmación, actuando el consumo de agua de mar registrada como un revitalizador, eliminando el uso excesivo del aceite y de la sal de mesa.

\section{DISCUSIÓN DE LOS RESULTADOS}

En una lámina se pone una gota de agua de mar junto con una gota de sangre obtenida de un pinchazo en el dedo pulgar. A la observación al microscopio con lente de $100 \mathrm{X}$ se observa que la capacidad de formar un trombo disminuye con el agua de mar, y se observa el apilamiento de las plaquetas de tres en tres, hasta continuar con su desintegración. Para corroborar esos resultados, se hizo la entrevista analizada anteriormente, para saber cómo actuó el agua de mar en personas que la han bebido por años, antes y durante la pandemia, y cómo la utilizan.

Desde el punto de vista biológico el agua de mar no es una vacuna biológica por excelencia, ni mucho menos garantiza una defensa ciento por ciento eficaz contra el virus del Covid 19, Sars 2 pero su administración actuó como un anticoagulante en el 99\% de los casos, ante las características proteicas del virus pandémico, al desintegrar la estructura proteica del sistema coronario, caracterizada por sus aminoácidos. Al recibirse el agua de mar hipertónica con el poder de los metales alcalinos que contienen sirvieron para aumentar el poder inmunológico de aquellas personas entrevistadas y encuestadas que no la padecieron pero que se administraban agua de mar antes de la pandemia, que corresponden al $15 \%$ de las personas entrevistadas, pero también como un elemento antioxidante y de laceración de esa estructura dependiente del virus por el nitrógeno, ya que el sistema pulmonar lo tenía, y el virus para sobrevivir, al ser proteína, su estructura se alimentaba del nitrógeno de los pulmones; el agua de mar, cambio el territorio en el que se desenvolvía el virus. Ninguna de las personas refiere al interrogatorio que fue fácil la lucha contra el virus, pero que una vez consumida el agua de mar durante la primera, segunda y tercera semana de haber sufrido la virulencia, lograron mejorar y respirar como antes de la pandemia. Solo en cuatro comunidades de nuestra serranía por voluntad propia se proveyeron de agua de manantiales marinos sin procesar y en relación al número de habitantes y al análisis por kilómetro cuadrado, comparado con otras partes del Ecuador, la morbi mortalidad es inferior al $40 \%$ en comparación con la media poblacional.

La única explicación científica de cómo el agua de mar salvó la vida del 99\% de las personas tratadas entre las semanas primera, segunda y tercera desde el momento en que se infectaron y ese $1 \%$ acudió a la última semana del ciclo virulento, - además con antecedentes de patologías malignas, - que era en la cuarta semana: es por los elementos que contiene, unos metales, otros como el magnesio que 
tiene la capacidad de aumentar el poder inmunológico y anticoagulante natural en su derecho natural quienes la bebieron para su supervivencia y ahora lo cuentan.

\section{CONCLUSIONES Y RECOMENDACIONES}

En la preparación de los alimentos se utilizó una balanza electrónica para establecer el gramaje de los alimentos para calcular la cantidad de minerales que iban por ración, y un vaso de precipitación, para calcular el volumen, además de cucharas que contenían la cantidad generalmente utilizada, y la sal de la mesa no se utilizó pero sí un estudio comparativo de la misma con el cloro y el sodio separando los componentes en el agua de mar. Así se deben considerar los elementos para la dieta de los hipertensos, diabéticos, colitis, obesidad, etc. Por ejemplo, el huevo también contiene yodo, y como son aproximadamente 150 ug los que se necesita, al preparar un huevo en la sartén, con agua de mar y no con aceite, es posible una buena combinación de yodo. En la preparación de la sopa, al hacerlo con $50 \mathrm{ml}$ de agua de mar, aporta una cantidad de yodo, que la carne la complementa.

Ante el interrogatorio, muchas de las familias, la utilizaban en forma dosificada en ensaladas que contenían: cebolla, pepino, tomate y zanahoria rayada. Otros utilizaban la piña en rodajas en un recipiente con $20 \mathrm{ml}$ de agua de mar; y el sabor era agridulce y otros bebian 60ml que al isotonizarla daban una cantidad de $240 \mathrm{ml}$ por dia. El $70 \%$ de las familias tenían entre sus abuelos y padres antecedentes de: cáncer de mama, cáncer de tiroides, cáncer de próstata, y no manifestaron reacciones adversas, mas bien reportaron mejora de la condición y sus niveles de las hormonas de la tiroides eran muy aceptables.

El tratamiento de agua de mar, sufre una brecha cultural en la población. Su uso amerita un dominio de personal sanitario ampliamente formado y entrenado, no solo en lo bioquímico, sino también en la administración de la misma

El agua de mar llevada al laboratorio directamente del mar, no debe consumirse si previamente no es tratada. El beneficio del agua de mar bebible y en el consumo humano, es loable. Pero el cuidado de su consumo debe ser dosificado y regulado para recibir todos los beneficios del agua de mar.

Los otros valores de la administración correcta del agua de mar como vía nutritiva para la terapéutica, deben establecerlos las universidades y escuelas politécnicas en el consumo del agua de mar con los alimentos y en cada una de las patologías. En caso de colitis, determinar cuál es la cantidad de agua de mar recomendada por la tolerancia al fósforo, que en el agua de mar es de 0,12 mg y que se debe convertir matemáticamente mediante regla de 3 cuanto se debe consumir de agua de mar en un diabético, en paciente con cáncer, en caso de pruebas de atletismo, de natación. Es decir, la comunidad científica está muy por debajo de lo que las comunidades del norte del Ecuador, ya por experiencia propia ya la consumen, sin embargo hay que recomendar su uso por cada patología cruzando la información con la 
sintomatología y exámenes de laboratorio, tal como el informe que le llega a Esencia Marina obtuvo en el año 2000.

Si se adquiere una cultura del consumo correcto, los beneficios son enormes, mientras tanto se está trabajando con una joya de la naturaleza que se la puede utilizar en forma poco técnica pero que los estudios de campo, demuestran innegablemente las ventajas de su consumo moderado. El consumo no moderado puede acarrear cualquier desventaja como el consumir grasas en exceso, o glucosa en exceso. La diferencia es que muchos alimentos necesitan del calor para ser consumidos, o no como es el caso de las frutas; pero si la fruta no se la lava igual el problema se viene con una parasitosis.

Otro dilema moderno es que si el agua de mar pueden ser administrada por otras vías tradicionales. Si el uso en otra forma de administración la convierte en nociva o no. Para eso se realizó un análisis de su uso en cerca de 8 provincias del Ecuador, que presentaban diversas patologías o enfermedades contagiosas adquiridas desde 2015 a 2021. 


\section{REFERENCIAS BIBLIOGRÁFICAS}

Aguirre , C., Chávez, T., García , P., \& Raya , J. C. (2007 ). El silicio en los organismos vivos . Interciencia Alarcón Vera, A. L. (2018). El boro como nutriente esencial . Tecnología Producción .

Braunstein , E. (2020). Anemia debida a hemorragia abundante. Obtenido de https://www.msdmanuals.com/es-ec/hogar/trastornos-de-la-sangre/anemia/anemia-debida-a-hemorragiaabundante

De Salinas Santamaría, A. M. (2018). Rioja Salud. Recuperado el 06 de julio de 2021, de https://www.riojasalud.es/servicios/endocrinologia-y-nutricion/articulos/diabetes-gestacional

Esteva , E. (2017). Ámbito farmacéutico. Obtenido de Trastornos tiroideos: https://www.elsevier.es/esrevista-offarm-4-pdf-X0212047X10875655

FAO . (2018 ). Los Minerales . Obtenido de http://www.fao.org/3/w0073s/w0073s0e.htm

Flórez, D. A., \& Bernabé Calle, B. V. (2015 ). El agua de mar en la alimentación y en la terapéutica . Boletín de la Sociedad Española de Hidrología Médica Vol. 30, 37- 55.

García Casal , M. N., Landaeta, M., García , O., García, D., Franquiz, J., Murillo , C., . . Puche , R. (2013). Valores de referencia de hierro, yodo, zinc, selenio, cobre, molibdeno, vitamina C, vitamina E, vitamina K, carotenoides, polifenoles para la población venezolana. Revista de la Sociedad Latinoamericana de Nutrición. Obtenido de Archivos latinoamericanos de nutrición : https://www.alanrevista.org/ediciones/2013/4/art-10/

Hereza , D. (2020 ). La actualidad de la Crítica de la Razón Pura: parte práctica . Revista estudios kantianos.

Ilari, M. T. (2021). Talasoterapia: terapia alternativa. Agua de mar: salud y desarrollo humano/ Trans pandemia qué hacer. Éxodo: Revista crítica de pensamiento y difusión socio cultural, política y religion.

Jades Piedra, C., Jaden Piedra, F. A., Flores Mendieta , C., \& Vera Alava, J. (2018 ). Caracterización microbiológica de agua marina en las zonas costeras de Manabí. Ediciones UTM .

Jaramillo Arbeláez, P., Zapata Bailarín, J., Mesa Vásquez, Y., Ochoa Ochoa, M., \& Arévalo Acosta , K. (2020). Comparación de parámetros hematológicos y morfología celular en muestras de sangre con EDTA K2 y EDTA K3. Medicina \& Laboratorio .

Kontrolab. (2019). Manual electrolitos PL 3. Obtenido de https://desego.com/wpcontent/uploads/2019/05/Manual-Electrolitos-PL3.pdf 
Liteplo , R., Gomes, R., \& Malcolm, H. (2002 ). Fluorides. WHO Library Cataloguing-in-Publication Data.

Meza Lopehandia, M. (2018). Negacionismo y libertad de expresión . Asesoría Técnica Parlamentaria . Ordavas Baines, J. P. (s.f.). Farmacocinética .

Ramírez, H., Zárate , P., García , M., De la Torre, O., Israde, I., \& Meulenert Peña, Á. (2009 ). Disolución de sílice biogénica en sedimentos de lagos utilizados como bioindicadores de calidad del agua .e-Genesis , 1 .

Sánchez Quezada, F. (2018). Maixmail.com. Obtenido de Tiroides y nutrición: http://www.mailxmail.com/curso-tiroides-nutricion/recomendaciones-ingesta-diaria-minima-yodo 